\title{
Narrativa centroamericana: frontera, violencia y exilio. Apuntes para una crónica de la corrupción
}

\section{Central American narrative: border, violence and exile. Notes for a chronicle of corruption}

\author{
Norma Angélica Cuevas Velasco \\ Universidad Veracruzana, México
}

\begin{abstract}
Resumen: Centroamérica ha sido campo fértil para la consolidación de una literatura ligada a los conflictos de identidad que enmarcan otro gran número de problemas sociales y políticos. A pesar de ser parte de una región que guarda una riqueza y similitud natural y antropológica vasta, es evidente que existe un afán colectivo por señalar las diferencias ideológicas y culturales que existen en la región. El artículo busca exponer cómo se construyen estas segmentaciones, cómo se erigen fronteras discursivas que mantienen a raya la fraternidad y profundizan las brechas que se forman entre las zonas limítrofes de estas naciones tan relacionadas entre sí por factores que van más allá de la coincidencia geográfica.

Palabras clave: Frontera, similitudes, diferencias, violencia, corrupción.
\end{abstract}

Abstract: Central America has been a fertile ground for the consolidation of a literature linked to conflicts of identity that frame a number of other social and political problems. Despite the fact of being part of a region that bears a similarity in the natural and anthropological wealth, it is clear that there is a collective effort to point out the ideological and cultural differences between the region. The article to expose how these cleavages are built as discursive boundaries that keep in line the fraternity and go in depth the gaps that are form between the border areas of these nations as related by factors beyond the geographical coincidence.

Keywords: Border, Similarity, Difference, Violence, Corruption.

Recibido: 31 de diciembre de 2016 Aceptado: 14 de marzo de 2017 


\section{Intención y ruta de viaje}

En un primer intento por reconocer algunas rutas probables dentro de la nueva cartografía de la literatura centroamericana, propongo estudiar un corpus literario que busca atender el género narrativo escrito por autores de origen centroamericano y que, además, las historias contadas en sus obras acontecen en esa geografía. El conjunto de textos se integra por cuentos, novelas cortas y novelas, con la intención de mostrar aquí, mediante la glosa del resultado de un análisis narratológico elemental previo, las tematizaciones, los tipos de personajes y los espacios de enunciación que configuran el universo discursivo de esta narrativa centroamericana de la segunda mitad del siglo XX e inicios del siglo XXI; es labor necesaria identificar las constantes formales en esta literatura para ir construyendo, de a poco, una poética que enfatice las particularidades de esta manifestación artística respecto de otras regiones. Para ello, se comentan nueve textos artístico-literarios representativos de aquellos ejes formales (temas, personajes, voces y puntos de enunciación), que abonan al despliegue de la existencia de una poética artística atravesada por la hibridez cultural en tanto su referente principal son los espacios intersticiales, es decir, las fronteras: geográficas, políticas, ideológicas, económicas, morales, poéticas, etcétera.

Interesarse por la frontera, tanto en el proceso de creación como en el de la crítica, obliga a generar una serie de estrategias de comprensión en un horizonte múltiple y variado respecto a las circunstancias de producción y recepción, intercambio, apropiación o negociación cultural donde inevitablemente se pone manifiesto las expresiones de violencia causadas por los desplazamientos migratorios, el exilio y, sobre todo, la corrupción que impera en América Latina. 
Dado que la genealogía del concepto de frontera es múltiple, ubicarlo como categoría de análisis en los estudios literarios conlleva la tarea de la redefinición. No obstante, el trasfondo de reflexión teórica que permite vislumbrar y elucubrar en torno a la posibilidad discursiva de dar los primeros pasos para la integración de una poética de la hibridez cultural en la literatura centroamericana; (a partir de la figuración y configuración artístico-narrativo de la frontera, la violencia y el exilio), se encuentra en las propuestas de Néstor García Canclini (2001), Fredric Jameson (2004), Marisa Belausteguigoitia (2009), Mónica Szurmuk y Robert Mckee (2009), en tanto identifican y atienden desde múltiples disciplinas, la complejidad de nuevos asuntos o problemas ubicados en los campos humanísticos; dichos asuntos son propiciados por las transformaciones en los espacios de contacto entre los distintos campos del saber y en las diversas formas de organización social en el contexto de la modernidad y su debate con lo posmoderno, principalmente, desde el punto de vista económico, político y cultural. Dichas zonas de contacto van abriendo intersticios que dan cabida a lo fragmentario, a lo global, a lo heterogéneo, a lo híbrido.

Las fronteras in/visibilizan todo aquello que puede colindar; oponerse u ocultarse. Su función epistemológica y crítica radica en el hecho de transparentar los efectos del ejercicio del poder y la resistencia. Estos límites apuntan a los gestos de resistencia que proponen nuevas colectividades o retornos estratégicos a lo local con el fin de revisar paradigmas estrechos de identidad. Este cruce y trazo de fronteras como delimitación alternativa de nuevas colectividades transnacionales, con su consiguiente revisión de identidades evidencia los mapas y geografías que surgen a partir de la resistencia, la lucha y representación "desde abajo", para una sociedad económica y socialmente justa y equitativa (Belausteguigoitia, 2009: 106-107). 
La constitución del concepto de frontera en Centroamérica adquiere una serie de características distintas a las entendidas entre el territorio mexicano del norte y los Estados Unidos. Esta idea de separación, desde finales del siglo XIX, es constante y se consolida, ya entrado el siglo XX, en los territorios limítrofes de los dos países, entendidos como puntos de reunión y congregación de distintas culturas y formas de vida que, al pasar por una serie de procesos complejos apropiación/desapropiación, van mostrando en los bordes, en su umbrales o intersticios, núcleos uniformes distanciados de aquellos que les dieron origen; son producto efectivo de la hibridación. En Centroamérica, las diferencias físicas, topográficas, léxicas, etcétera, son casi imperceptibles, por lo que se percibe como una totalidad homogénea sin que en realidad lo sea; la zona limítrofe se ha ido desdibujando no sólo territorialmente, también ha tenido consecuencias en la sociedad y en sus expresiones culturales y artísticas, entre ellas la literatura.

En la creación artística verbal centroamericana, el concepto de frontera adquiere, principalmente, dos sentidos: límite (en tanto separación, detención y reconocimiento de territorios diversos) y umbral (simultáneamente puerta de acceso y de salida, mezcla de dos territorios). En esta amplia concepción de frontera conviene citar nuevamente la reflexión de Belausteguigoitia: "Las fronteras separan, unen, delimitan, marcan la diferencia y la similitud, pero también producen espacios intersticiales, nuevos espacios que inauguran relaciones. Pueden ser burladas, acatadas, cruzadas, transgredidas, imaginadas, reales, reinventadas y destruidas. Confinan y liberan. Protegen y torturan" (106-107).

Desde el punto de vista geopolítico, la concepción de las fronteras individuales, que separan a un individuo de otro distinto pero semejante, son las que nutren la idea de separación entre comunidades, de una misma localidad o nación, con sus semejanzas y diferencias; y éstas, a su vez, configuran la noción de Frontera (así, 
con mayúscula): la del Norte, el límite con Estados Unidos y el american dream, donde sí existe esa diferencia entre yo y el otro. Así, podríamos entender por fronteras individuales aquéllas que distinguen a los individuos desde su nacimiento y formación en tanto personas: género, características físicas, religión, clase social (Canclini, 2003); así, por fronteras entre comunidades se conciben las diferencias que existen entre los individuos de un territorio a otro, sea municipio, estado o nación, como: etnias y su estilo de vida, costumbres, cultura, visón de mundo; como Frontera, se comprende la zona entre México y Estados Unidos, donde se genera una sociedad híbrida y sincrética que, aparentemente, elimina los rasgos de distinción entre los individuos.

El interés genuino por comprender las diferencias no parte de definiciones, sino de preguntas, cuyas repuestas no serán verdades clausuradas sino campo para la proliferación de estrategias de análisis, interpretación y comprensión de los textos y su discursivización. En los estudios literarios, preguntar por quién habla y desde dónde se enuncia y para quién (Pimentel, 1998) resulta fundamental para entender los tejidos ideológicos y éticos que son inherentes a las relaciones de sentido que la obra produce; lo mismo sucede con la detección del núcleo temático y los recorridos que los personajes realizan para configurar su identidad narrativa. Y es este aspecto el que constituye la base argumental para una ulterior apuesta por una poética literaria centroamericana de entre siglos.

En esta ocasión, el objetivo es hacer crítica literaria sobre un tipo de literatura que tiene como reclamo principal atender y comprender el contexto histórico-social en el que fueron escritas estas narraciones, a fin de dar cuenta de los procesos de construcción y transformación de dicha literatura, haciendo énfasis en los rasgos concordantes entre ellas al mismo tiempo que se señalen las diferencias que se presentan en su interior. 


\section{Viaje y paisaje: primera mirada}

Los textos literarios a los que haremos referencia en este artículo son: "Bocado de viento" cuento de Arturo Arias, publicado en la antología Cuentos centroamericanos (2001), recopilada por Poli Délano; "Los héroes de la fiebre" de Eduardo Bahr y "El zoológico de papá" de Lizandro Chávez Alfaro (ambos relatos aparecen en la misma antología, pero fueron editados por primera vez en $E l$ cuento de la guerra (1971) y Los monos de San Telmo (1963), respectivamente). Incluyo también "La pregunta" del libro de cuentos Héroes a medio tiempo (1998) de Justo Arroyo, incluido en la décima edición de la ya canónica antología El cuento hispanoamericano de Seymour Menton. Del género novela, se seleccionó Piedras encantadas (2001) de Rodrigo Rey Rosa, El arma en el hombre (2001) de Horacio Castellanos Moya, Nuestra señora de la noche (2006) de Mayra Santos-Febres, La mitad del infierno (1993) de Óscar Palacios y Te están buscando (2004) de Carlos Vadillo Buenfil.

A pesar de las diferencias en los años de publicación, se podría señalar de inmediato una característica común: las obras están inmersas en el clima hostil de la represión y atienden, en muchos casos, a direcciones específicas de un momento histórico en los países que constituyen la geografía representada en ellas. La violencia, la pobreza y los movimientos armados son los hilos que tejen las tramas. Con estilos que van desde la narración en tercera persona o la primera persona, el género epistolar, el monólogo interior, la crónica, ya sea con perspectiva masculina o femenina, adulta o infantil, los cuentos y novelas van configurando metáforas y símbolos de la sociedad moderna de una complejidad tal que la tornan incomprensible, inalcanzable e inabarcable.

Muy probablemente, en estas narraciones sea el miedo el elemento principal que conduce el hacer (o dejar de hacer) de los sujetos de ficción; el miedo es atmósfera creada como arma de 
los regímenes opresores. En "Bocado de viento", por ejemplo, se representa el patetismo al que pueden llegar los individuos en un medio donde las oportunidades son escasas o nulas, y las aspiraciones mínimas conllevan más desgracias que satisfacciones, como si tales grupos no tuvieran derecho a una mejor calidad de vida. En "Los héroes de la fiebre" se muestra la contraparte de la guerrilla, puesto que en los ejércitos nacionales el soldado también sufre, no siempre es su voluntad la que lo orilla a enlistarse; al final, todos sublevados, civiles, soldados- son víctimas de intereses que corresponden a esferas más altas de poder; se revelan las consecuencias de guerras inútiles. Ambos cuentos comparten el calor y sudor del trabajo "de aquel que lo convierte a uno en mina de sal" (Arias, 2001: 15), el de la muerte; la selva, generosa cuando los oculta y protege, pero también cruel e inhóspita cuando, junto con la desesperación, pareciera tragárselos y volverse laberinto.

En "El zoológico de papá" se halla, por otra parte, la parodia del sistema político y la forma de gobernar. Es importante observar que su contexto corresponde directamente al periodo de dictadura militar de Somoza García en Nicaragua y, específicamente, a una de las prácticas de tortura que acostumbraba a usar contra los rebeldes. Más velado es el discurso en "La pregunta", que parte de un evento tan cotidiano como la visita de un cliente (un anciano) a cierto restaurante y el triunfo de su exigencia, dice Seymour Menton: "En pocas páginas, el autor logra convertir una situación común y corriente [...] en una batalla dramática cargada de tensión" (2010: 735); aunque aquí la batalla no esté representada por armas ni en el terreno habitual, resulta clara la lucha del individuo contra el sistema, y en el peculiar triunfo queda la esperanza para los impotentes frente a cualquier institución o gobierno.

En Nuestra señora de la noche se asiste al espectáculo de la avaricia, del derroche de aquéllos que han conseguido una mejor posición con respecto a sus "iguales", la ríspida convivencia entre 
habitantes de una misma zona, delimitados por los bares, los prostíbulos y el alcohol, mientras los otros son, primero, degradados, para después arrojarlos al olvido, al anonimato.

La falta de identidad es uno de los planteamientos en Piedras encantadas, pues la red de corrupción exige el silencio para conseguir más víctimas, más inocentes al servicio de la mezquindad; en esta línea, Te están buscando expone, a través de su protagonista, las consecuencias del autoexilio; en esta novela el desplazamiento simboliza la transformación de la identidad y la posibilidad de cambiar el destino. Caso distinto presentan La mitad del infierno y El arma en el hombre, pues es la identidad de ambos protagonistas lo que se desea esconder, desaparecer; en el primero, es preciso perder el nombre, volverse exiliado político por haber cuestionado el régimen existente; en el segundo, es necesario cambiarlo, transformarse para seguir trabajando con el mejor postor, para continuar envileciéndose.

Un panorama general de estas narrativas centroamericanas conduce a la necesidad de plantearse preguntas acerca de los mecanismos de represión y sus consecuencias sobre el individuo, a encontrar los puntos de contacto en esta gran crónica de la tragedia, para describir la América Central de los magnicidios, el horror, la corrupción y la muerte.

Miradas y voces: espacios fronterizos y violencia

En el caso de la literatura centroamericana, en las narraciones breves, se encuentra un primer planteamiento sobre las pugnas existentes en los márgenes territoriales. Así, a partir del cuento "La pregunta”, de Justo Arroyo, cabe destacar el valioso trasfondo de una anécdota habitual que por el contexto se carga de significado. La importancia del relato recae en la figura del personaje principal, una fuerza heroica que se verá trasmutada en otros cuentos y nove- 
las, una suerte de épica centroamericana, donde los héroes-personajes sólo son en su intento de lucha, independientemente de los valores éticos que adoptan, contra la dominación. La narración es un juego sutil de miradas entre el viejo, los comensales del restaurante y los meseros; el platillo raquítico a precio desproporcional es la clara estafa de lo que en el cuento se denomina "capitalismo salvaje". Los ojos fungen como la primera fuente de reclamo, hay una mirada quemante que fulmina y provoca apartar la vista, pero es una mirada que todo lo rodea y resulta inútil evadirla. A través de la mirada el personaje se instaura en ese espacio y su presencia es reconocida, él es porque antes que hablar, mira. Después asistimos al silencio, la narración hasta este punto ha tenido un ritmo en el que las miradas no detienen el fluir cotidiano de la actividad en un restaurante cualquiera: conversaciones, los ruidos del choque de platos y cucharas, la espera que avanza en la fila de servicio. El movimiento en el cuento se detiene para dar paso a la pregunta.

Lo importante aquí es que el personaje representa la voz colectiva que solicita ser reconocida por el sistema, del mismo modo que la presencia del protagonista es reconocida en el restaurante, abanderada por la pregunta-queja, "aquella que nadie antes de él se había atrevido a formular”: “- ¿Cuatro dólares por dos telitas de mierda?" (733) y que desemboca en un cambio real y provechoso para todos. La lucha simbólica que representa la narración es la del individuo contra el sistema: el restaurante, los cocineros, el anciano, los comensales; en todo enfrentamiento existen dos bandos, la separación entre ellos se erige como una frontera de orden moral.

La relación entre literatura y contexto histórico-social en "El zoológico de papá", de Lizandro Chávez Alfaro, nos lleva a pensar en la narrativa como recurso contra la dominación, una suerte de denuncia, tal como sucede en "La pregunta". Este cuento adquiere importancia bajo el conocimiento del periodo de dictadura militar de la familia Somoza García en Nicaragua, de 1934 a 1979, y que 
constituye una etapa difícil de superar en la memoria nacional, aunada al colectivo que recuerda y repite todo tipo de prácticas y anécdotas que se le adjudican. El texto desarrolla los mecanismos de sometimiento, evidencia cómo el miedo es el recurso clave de la opresión y cómo muchas veces los hombres que tienen la osadía de enfrentarse a la figura de poder son reducidos a animales. Así, el hecho de que a Anastasio Somoza García, entre otras atrocidades, se le atribuya haber mantenido en la casa presidencial un "zoológico" conformado por una colección de fieras salvajes, cuyo fin particular era la tortura contra cualquier personaje incómodo que pudiera surgir, da pie a la configuración de este relato.

El narrador y personaje principal es una voz cuasi-infantil que tiene interiorizada la idea sobre el poder. A los trece ańos, el protagonista ha recibido el nombramiento de coronel, estudia en un internado en Schenectady al que le deberá su formación política y del que ha aprendido que ninguna nación latinoamericana es comparable a los Estados Unidos, que siempre ha de anhelarse lo otro: "Una de las cosas que voy a ordenar cuando sea presidente es que construyan un gran tubo de aquí a los Estados Unidos para que por allí nos manden aire. Así ya no haría tanto calor, y a lo mejor, respirando ese aire, la gente de acá llega a parecerse a la de alla”" (144).

El argumento se asienta en que el futuro gobernante ostenta su poder contra un preso político, lo arroja a las fieras sin que medie una orden de su padre, es decir, una travesura de pequeño dictador, una imitación de aquel que le enseñará a gobernar. Es su justificación lo que nos advierte de la intransigencia que practica y que es común en Nicaragua: "Yo sólo quería que el hombre dejara de pensar lo que pensaba; nada más" (148); para rematar con una sentencia que invita a la reflexión cabal acerca del anhelo por lo otro, que tal vez sea solamente cuestión de perspectivas y depende de quien la enuncia con respecto del aquí y ahora donde se encuentra: 
"A esta hora de la tarde es bonita [la ciudad, Nicaragua] y me gusta más que Shenectady, tal vez porque sé que aquí mando yo" (148).

"Los héroes de la fiebre", de Eduardo Bahr, retoma el miedo que surge de los enfrentamientos entre grupos armados pero desde otra perspectiva: aquí, los soldados al servicio del poder y la sociedad civil se vuelven víctimas, ya que prevalece un estado de confusión respecto de los motivos de la guerra. También, puede leerse como la figuración del conflicto entre El Salvador y Honduras que detonó en 1969. Las tensiones políticas entre las dos naciones no soportaron el impacto de enfrentarse en la cancha de fútbol, lo cual, antes que reducir al absurdo el conflicto, denuncia un patético furor nacionalista que causó increíbles injusticias.

El flujo de salvadoreños hacia Honduras debido a las pésimas condiciones en El Salvador para conseguir un trabajo digno (provocadas por los grupos de poder que controlan la tierra, los medios de producción y la economía por completo), constituyó la raíz de la disputa. Este es el caso del protagonista del cuento, un joven hondureño, de descendencia salvadoreña, cuyo nombre se ignora y que relata en la intimidad del lenguaje epistolar los efectos de la guerra. A diferencia de "El zoológico de papá" donde es evidente el ejercicio desmedido del poder, en este cuento se expone la contraparte: los estragos que causa dicho ejercicio en los sectores más débiles, incluso, el protagonista afirma: "no sé qué me va a pasar cuando le dispare el primer tiro al cuerpo de un hombre como yo" (70).

"Aquí nadie sabe quién es quién" (69), nos dice en las primeras líneas el protagonista y apunta a la ambigüedad entre civiles y soldados, hondureños y salvadoreños, amigos y enemigos: "Hace poco un tipo de esos me preguntó que si yo era de los enemigos o que si era de los nuestros" (69). Se juega constantemente con la idea de la aparente mezcla de dos culturas que se resisten a aceptar que desde tiempos pasados son la misma. 
En el artículo "Guatemala hoy" de Pantxika Cazaux publicado en Casa del tiempo en 1983, la autora hace un recuento de la situación política y económica de esta nación hasta el golpe de estado del 23 de marzo de 1982, que llevó al poder al general Efraín Ríos Montt. Describe, entre los hechos, la política de "tierra arrasada": "consistente en destruir completamente algunos pueblos para obligar a la población a reagruparse en los mal llamados «pueblos modelo"” (Cazaux, 1983: 32), pueblos creados por el régimen con la finalidad de vigilar y evitar los contactos de las personas con la guerrilla. Esta forma de terror implementada, además de la tortura y de las masacres públicas, provocó que miles de guatemaltecos buscaran refugio en territorio mexicano.

Así como en "Los héroes de la fiebre", el movimiento militar causado por la guerra mantiene rezagados a los habitantes en sus lugares de origen, en "Bocado de viento", de Arturo Arias, es el conflicto entre la milicia y los guerrilleros el que ocasiona el estado de sitio en las "tierras arrasadas", con la finalidad de que los sublevados no encontraran partidarios en los poblados incomunicados que pudieran servirles de refugio. Desde este contexto es posible la lectura del cuento, que alude directamente a la violencia del ejército guatemalteco contra la subversión. En él se narra la frustración del personaje principal, Petronio, que ni siquiera puede asirse al mínimo sueño de ser propietario de un refrigerador, símbolo patético de poder y propiedad que lo acompañará hasta el día de su muerte.

Petronio migra de Escuintla, donde "sólo podía ganarse la vida escupiendo fuego y de eso nomás le quedó la voz ronca y la imposibilidad de saborear la comida", hacia Nuevo Amanecer donde "sí tenía tierrita aunque fuera a fuerza de arrancársela a la selva a puro pulso" (32); la compra del refrigerador y su traslado a Nuevo Amanecer es un conjunto de peripecias, cuya recompensa dura poco: la refresquería "Frescura petenera", administrada por Petro- 
nio y Romualda, su mujer, otorga a sus dueños prestigio en toda la zona; no obstante, dicho establecimiento se convierte en el punto de reunión de los guerrilleros; esto origina la llegada del ejército y, simultáneamente, la degradación del poblado y sus habitantes: "Petronio ya se preparaba para una nueva expedición hasta Ciudad Flores, cuando empezaron a correr los rumores de que iba a entrar el ejército porque Nuevo Amanecer era un "pueblo subversivo»" (29); aun así, se dirige a la ciudad con una comitiva; en el trayecto son detenidos, maltratados, humillados y estafados por los militares, regresan con las manos vacías. Ante estos acontecimientos, amedrentados por la milicia y persuadidos por los guerrilleros, deciden abandonar su tierra y se dirigen a la frontera mexicana.

El trayecto hacia el otro lado, alcanzar la frontera mexicana, implica sufrimiento físico y emocional para todos; sin embargo, Petronio y Romualda "juraron que nunca, mientras Dios les diera vida, se separarían de la refri" (36), pues "sufría[n] de pensar que algo le fuera a pasar a la refrigeradora: que se la llevara la corriente, que se diera vuelta, que se la fueran a quitar del otro lado esos que se llamaban mexicanos, que decían que tenían dos cabezas y cuatro manos" (37); incluso, estuvieron dispuestos a sacrificar su vida para salvaguardar el preciado objeto, aunque entendían que "estaba escrito que gente como ellos sólo estaban destinados a oler el sudor exhalado por las penas, a marearse con el dolor de las derrotas cotidianas" (41).

Las fronteras están en cualquier sitio: la discriminación las acentúa. Para estos personajes vivir en la línea de la muerte y aceptarse en la orfandad define su horizonte de nostalgia por la tierra no ajena, por el idioma propio, por la identidad. 
Violencia y espacios fronterizos: las novelas

Óscar Palacios muestra en La mitad del infierno, desde México, el ambiente en la región del Soconusco y su límite con Guatemala, ya concluida la Independencia de ambos países, cuando, en 1838, inicia la guerra civil entre las Provincias Unidas de Centroamérica, cuya única posible salvación era cruzar el río Suchiate y refugiarse en tierras mexicanas.

Bajo el mando del General Arroyos Mon, los militares toman la Universidad de Guatemala, y Álvaro Vidal, el protagonista, estudiante de derecho, escritor del periódico de la Universidad, "acusado por el alto delito de pensar" (83), se convierte en prófugo de la justicia; perseguido, cruza la frontera con México. En su recorrido, tiene la oportunidad de observar cómo gente de diferentes regiones se traslada a tierras mexicanas, escucha diversas conversaciones donde las voces afirman que este suelo es más seguro, que el pueblo no entiende por qué debe defender a su país, pero entiende que debe trabajar para comer.

Al escuchar los diálogos que sostiene la gente alrededor, Álvaro no encuentra diferencia entre su tierra y ésta. Continúa su recorrido hacia Cacahoatán guiado por don Gonzalo, ministro en la oficina de Hacienda, que más tarde se convertirá en compañero de parrandas y reflexiones. Es él quien le enseña a Álvaro cómo funciona el poblado, le muestra las diferentes zonas y lo que en ellas puede encontrar, lo inicia en la vida disipada llevándolo a un lugar non sancto, como él mismo declara. Durante su visita a la zona de tolerancia, Álvaro y don Gonzalo intercambian opiniones sobre la situación de América Latina; uno y otro coinciden en que, debido a los cambios de Gobierno y al mal manejo del presupuesto, los poblados pierden poco a poco sus características e identidad: el Gobierno, en su afán por modernizar Latinoamérica, empieza a "agringar" las zonas principales de los países: en el sur de Guate- 
mala y en el norte de México se encuentran los territorios ambiguos; mientras, las regiones fronterizas, como consecuencia de las guerras, sólo conocen hambre, miseria, prostitución, violencia. "El paisaje va dejando de ser rural para tomar la vestimenta de urbano. Anuncios en inglés contrastan con los rostros de un pueblo donde más de la mitad de la población es indígena pura, la devastada presencia de una grandeza maya del ayer. Ciudad de Guatemala está allí, cosmopolita, aparentemente ajena a la dramática realidad que vive. Ciudad que se maquilla, como todas las urbes latinoamericanas, para no demostrar las llagas que la circundan" (66-67). Ante la realidad que observan, el paralelismo entre los dos países sobrepasa cualquier límite: no sólo la topografía es semejante ("como si el Soconusco se alargara o Guatemala se extendiera”), el clima, los problemas, el hambre, la guerrilla, el idioma, casi todo se percibe igual; pocas son las diferencias que pueden detectarse entre un país y otro, para Álvaro la única diferencia se encuentra en el lenguaje: "La única frontera son nuestros modismos, piensas. Mientras, las voces te confunden, crecen, te exasperas: '¡patojo, pásame el pichel con el refresco!...' 'Cuando fui a buscar candelas para mi bus tuve que darle reata a un canche que andaba cantineando a mi traída"' (132). Indeterminación, ambigüedad, el mismo lado; no existe diferencia entre territorios cuando se encuentran en guerra o cuando son invadidos por la modernidad y la mercadotecnia; ni cambia el paisaje ni el clima ni la raíz indígena de un lado a otro del Suchiate; tampoco el sufrimiento ni la muerte.

Rodrigo Rey Rosa, en Piedras encantadas, se encarga de señalar la otra cara de Guatemala, una realidad sórdida que infesta una sociedad como un eco desolador. Situada la novela en la ciudad de Guatemala, donde un niño belga, hijo adoptivo de una pareja de nuevos ricos, es atropellado en la Avenida de las Américas. Las investigaciones arrojan que quizá se trata de un intento de secuestro o asesinato para dar un escarmiento al padre adoptivo de 
Silvestre. Este acontecimiento, a su vez, se engarza con la historia de Joaquín, quien podría ser o no el protagonista, y que desde su condición de extraño se vulnera ante lo otro, Guatemala que le es ajena. Una voz interna parece advertirle las razones que lo separan de ese territorio, que en el nombre de sus avenidas ostenta la ironía: "Paseo de la Reforma. La despiadada reforma que abolió el derecho de los indígenas guatemaltecos a sus tierras comunales para que fueran convertidas en plantaciones de café" (27) o el bulevar Liberación "(conmemorativo del derrocamiento del primer intento de gobierno democrático en el istmo)" (65).

Verse involucrado en un hecho fortuito, entre los tantos que constituyen la cotidianidad de un lugar como Guatemala, pondrá en evidencia la enfermedad crónica del país: tráfico de influencias e información, representada en el personaje de Franco Vallina, de quien se dice: "Poseía una envidiable inmunidad a los achaques de conciencia, indispensable para todo abogado ambicioso que quisiera abrirse camino en Guatemala. Abogángsters, les llamaban aquí a los de su clase" (30).

Dentro de los personajes-tipo, asumiendo su rol en las grandes ciudades, se encuentra la pandilla infantil Piedras encantadas, quienes se dedican a atracos menores, tráfico de drogas e información, y tendrán un papel decisivo en la investigación del crimen contra Silvestre, el niño belga. Mientras la policía se erige como el principal enemigo, el único que demuestra interés por el esclarecimiento del caso es el inspector Rastelli, quien se encargará de atar los cabos sueltos y procurar la seguridad de Silvestre.

Finalmente, hay en la novela una serie de factores que se constituyen como frontera: la violencia, la corrupción, la diferencia de clases. Cada individuo se vuelve extranjero, expatriado, cada personaje vive al límite de la desolación. De esta manera se inscribe la metáfora final: Guatemala, ciudad de piedra y aire volcánico, habitada por muertos. 
El arma en el hombre permite observar desde otra perspectiva el escenario del conflicto armado, que generalmente se desarrolla en lugares intermedios entre las capitales y provincias de un país. A diferencia de los cuentos antes mencionados, donde permanece la visión de los vencidos; aquí, a través de los ojos de Robocop, se revelan los métodos de sobrevivencia de un desmovilizado militar que ha perdido su sentido de pertenencia al disolverse el conflicto guerrillero de El Salvador y es incapaz de integrarse a la vida civil, ya que lo único que sabe hacer es pelear. Desde el inicio de la novela, Robocop se distingue de los demás por sus aptitudes; además, aunque pobre, nació en la ciudad y estudió hasta el octavo grado. También gozó de la simpatía de sus superiores, quienes procuraron su adiestramiento constante; incluso él enfatiza su diferencia con respecto a los otros desmovilizados: "Los del pelotón me decían Robocop, pero a mis espaldas. De frente debían cuadrarse y decirme 'mi sargento', no sólo porque yo era el jefe, sino porque ni a golpes, ni con el cuchillo, ni a tiros alguno de ellos pudo ganarme; tampoco en táctica e inteligencia" (Castellanos, 2001: 10).

La transición de la guerra a un estado de relativa paz significó para el protagonista su transformación: "Convertirme en civil fue difícil [...]. No me podía imaginar de la noche a la mañana en un civil, en un desempleado" (12). A partir de este momento, Robocop empieza a vivir bajo la consigna: "si no estás conmigo, estás en contra mía”, por lo que, a lo largo de sus andanzas considera a los otros siempre sus enemigos: gobernantes, guerrilleros, población civil; poco a poco es reconocido en todos los ámbitos de la sociedad como un peligroso delincuente; para evitar su detención huye hacia Guatemala. De vuelta a El Salvador es capturado por las autoridades; durante su estancia en la cárcel recibe primero la visita de su madre y hermana, que llegan desde Estados Unidos y le ofrecen un trato: 500 dólares y su libertad a cambio de matar a su padre, y le advierten: "«Tendrá que ser con cuchillo", dijo mi 
madre, «un arma de fuego deja mucho rastro de aquel lado»" (65); y después la visita de Sholón, el kaibil guatemalteco: “'Sos una mula. El cerebro no se le saca a tiros al enemigo. El cerebro del enemigo debe sacarse con las propias manos, a golpes. Sólo así se le destruye la voluntad y la inteligencia. [...]Por eso estás preso, porque no entendiste nada cuando estuviste con nosotros', dijo el Sholón mientras se ponía de pie" (66).

Asegurada su salida de la cárcel, huye nuevamente hacia la frontera con Guatemala; pero esta vez llega más lejos: se establece en la hacienda Las Flores, ubicada en la zona fronteriza con México. Ahí, retoma su entrenamiento militar y "por fin lograba volver a ser lo que había deseado" (86). Su calidad de mercenario le asegura siempre un modo de empleo y subsistencia y la posibilidad de volver a cruzar de un lado a otro, pues las redes de comunicación entre narcotraficantes centroamericanos son una de las principales razones de los desplazamientos fronterizos. Después de una misión fallida en Guatemala, causada por unos mexicanos refugiados en Las Flores, el protagonista es, finalmente, apresado; los sucesos, lo llevan hasta Estados Unidos.

El cambio de un bando a otro de Robocop podría interpretarse, también, como un cruce de fronteras, pues si bien se inmiscuye en "diferentes organizaciones" cada una de ellas obedece a un interés superior, ya sea el gobierno o los narcotraficantes que operan de la misma forma; lo único que cambia, si acaso, es el lugar desde el que se realizan las operaciones, los medios de transporte y el papel moneda, por lo demás, hasta los nombres y seudónimos, el semblante físico, la topografía, el terror, son similares.

Así como Robocop transita libremente entre diversos países, sorteando las fronteras al servicio del mejor postor, Isabel Luberza, protagonista de Nuestra Señora de la Noche de Mayra SantosFebres, transgrede otro tipo de fronteras. Esta obra es la historia novelada de Isabel Luberza Oppenheimer, mejor conocida como 
"Isabel la Negra", enigmático personaje de Puerto Rico, cuya fecha de nacimiento se desconoce; mientras que la de su nunca esclarecido asesinato es el 4 de enero de 1974. Isabel llegó a convertirse en una figura influyente en la sociedad de su tiempo como dueña y regenta del mítico burdel Elizabeth's dancing club, que recibía a los hombres más ricos y poderosos del lugar. Esta novela es, además, la representación de la sociedad puertorriqueña fragmentada por la raza, la clase y el poder económico y cómo, ante ello, se reivindica un tipo de héroe, encarnado nuevamente en un personaje capaz de representar una colectividad.

Isabel es negra y pobre, por lo tanto sujeto marginal. Los personajes marginales abundan en la novela (los negros que se desempeñan como campesinos, lavanderas, sirvientes) en franca oposición a la clase social dominante (las familias blancas de origen español dueñas de los ingenios, los comercios, las fábricas). Nuestra Señora de la Noche es también la búsqueda de la identidad de esta clase, la lucha encarada en la cotidianidad a causa de un destino impuesto por la diferencia. La protagonista desde pequeña está consciente de su condición, de aquello que no le está permitido para la realización de sus ambiciones: "yo no pienso en el amor, don Demetrio. Quiero ser una mujer de medios, montar mi propio negocio'. 'Pues para eso tienes que buscarte a un parejo que te sepa entender y respetar.' 'Ay no, ni parejos, ni hijos, ni nada. No me quiero ver regalando barrigas, porque no las puedo mantener.' 'Pero ésa es una vida muy solitaria, Isabelita.' ‘Cómo la suya, maestro?’” (Santos-Fabres, 2006: 98).

La constitución de la identidad de Isabel está entre la feminidad mítica encarnada en la virgen negra (de la que siempre será devota) y el prototipo de mujer liberal que aprende en la figura de Luisa Capetillo, anarquista puertorriqueña, pionera del feminismo y sindicalismo en el país. Isabel por ser distinta seduce y la seducción es el poder que tendrá sobre los hombres y la sociedad. 
Minerva, prostituta del Elizabeth's, también en su momento ejerce la seducción sobre Luis Arsenio, quien se mantiene angustiado en el límite de lo que ella representa: "Su voluntad de hombre terminaría hecha sudor y leche entre las piernas de una negra. [...] supo que había traspuesto un límite. ¿Acaso aquel sentirse otro, literalmente otro, en la carne y en el momento de otro era hacerse hombre?" (39). Sin embargo, el deseo no oculta aquello que la sociedad juzga: "Todas eran superiores a ella, porque Minerva era puta y negra, y eso era lo peor que se podía ser sobre la faz de esta tierra" (78). Luis Arsenio Fornarís es hijo legítimo de una de las mejores familias de Puerto Rico, por lo cual no puede permitirse este desacierto, esta mácula que no lo deja en paz ni en sueńos. Pareciera que nunca logrará cohesionar su identidad, menos cuando se marcha a estudiar a Norteamérica y nota que allá no es nadie.

Por otra parte, también la identidad de Roberto Fornarís, el hijo que abandona Isabel, se encuentra escindida por no tener claro su origen: es un mulato que en los primeros años de vida no comprende por qué no se parece por completo a su padre y desea saber dónde está su verdadera madre, que no puede ser Doña Montse, la vieja negra que lo cuida, cuya relación es análoga a la imagen de la virgen negra con niño blanco en el regazo. Roberto posteriormente vivirá metiéndose en líos, hasta decidir enlistarse en el ejército, lo que años después lo llevará a conocer a su medio hermano, Luis Arsenio, y comenzar una relación fraternal y, así, cerrar el círculo de su existencia; es decir, en Luis Arsenio encontrará la parte que le falta, el lazo de sangre que al mismo tiempo los une y los separa, unión que tiene mayor fuerza en la escena final, cuando entre los hermanos cargan el féretro de Isabel.

Los de esta novela son personajes que viven en la frontera de lo que son, entre el ser y no-ser, las apariencias, lo cual se traduce en la angustia por una culpa que no les pertenece: ser aquello que los otros ven. 
En esta línea, se inscribe también Te están buscando (2004) de Carlos Vadillo Buenfil, quien ambienta su novela en la ciudad de México y Cali, Colombia. Desde el principio se establece una analogía entre la mujer y la ciudad, ambos como zonas donde se quiere o se puede estar: "Suele pasar con algunas ciudades lo que acontece con ciertas mujeres: tienes que desertar de sus geografías cuando apenas estás aprendiendo a amarlas" (15).

Te están buscando es la historia de Aspirino, un trompetista que se ve envuelto en la venganza de unos narcotraficantes contra miembros de su grupo de mariachi, quienes se dedicaban a la venta de drogas, motivo que lo obliga a huir del país. Aspirino ha vivido la infancia en Puebla; la adolescencia y la juventud en la ciudad de México, lugar donde ocurre la primera parte de esta aventura. Huérfano de madre desde muy pequeño, su nana María Chi, una mujer maya, queda a cargo de él y su hermano, al mismo tiempo que influye en su gusto por la música a través de la afición de ésta a los boleros.

Aspirino decide marcharse porque lo ha perdido todo: la mujer, los amigos, el trabajo y la seguridad. Los desplazamientos no son garantía de nada, pero la determinación de llegar hasta Colombia en una búsqueda que se antoja absurda, será el factor determinante en la construcción de la identidad del personaje. No obstante, la incertidumbre siempre está presente antes de su partida: el protagonista acepta con resignación su exilio: "Detrás de mí ya no queda nada. Los ligazones que sostenían mis puentes se han desatado, podridos ya. [...] Ciertas ciudades son como algunas mujeres: acaban tatuándose en la piel" (96).

La llegada a Colombia significa el choque entre dos culturas: la mexicana y la colombiana, al parecer unidas por el lenguaje, sin embargo no es del todo así: "Es raro eso de que un letrero te indique que no perteneces a este ámbito, a pesar de que uno se haga entender en el mismo idioma. Bueno, rectifico, uno cree que 
se entiende con los demás. Esa es la dolorosa apariencia” (101). En Cali, la búsqueda de Shirley se convierte en una búsqueda de sí mismo. Ahí, se encuentra con otros mexicanos: se vuelve amigo de Julián, escritor compatriota varado en Cali por una novela que no ha logrado escribir gracias a una beca que ya se ha gastado, con quien recorrerá los bares y centros nocturnos de la ciudad y le ayudará a colocarse en un mariachi para ganar dinero.

Finalmente, Aspirino descubre que Shirleyes, una militante urbana de las FARC, en su viaje a México como integrante de un ballet de danza contemporánea, tuvo el objeto de negociar con el cartel de Tepito (el mismo que asesinó a los amigos de Aspirino) un intercambio de cocaína por armas. El destino azaroso les permite reunirse en un motel, sin embargo, el mismo azar los separa: una vez terminada la cita son asesinados; entonces ciudad y mujer se desvanecen: "Hay ciudades, hay mujeres que se desmoronan como el aserrín con sólo invocarlas, [...] que se hunden y no dejan rastros, sólo breves indicios para reinventarlas" (186).

Fronteras narradas, identidades fragmentadas

Las narraciones de los migrantes, de los desplazados o exiliados, se ubican en la frontera y se definen por la violencia y recrean con cruda precisión sucesos cotidianos de la frontera entre México y Guatemala; entre México y Estados Unidos; entre Guatemala y otros país de América Latina; el minucioso registro de ambientes y lenguajes, el apego a la realidad y la intensa verosimilitud en la construcción de sus personajes provocan que esta narrativa centroamericana vaya más allá de los linderos de la ficción y establezca juegos discursivos y poéticos con otros géneros literarios; por ejemplo, con la crónica. El núcleo de sus relatos es la frontera, la frontera sur, la frontera norte, la miseria humana, pero también el desarraigo y la falta de identidad, con profunda huella de nos- 
talgia y melancolía en el ánimo de los sujetos fronterizos. De allí que estas narraciones sean, a un tiempo, muestra palmaria de la existencia de las poéticas de la frontera y de las fronteras poéticas y, también, de la estética de la violencia.

La narrativa centroamericana breve es el espacio literario donde se configura a los sujetos migrantes con cualidades extraordinarias, esas que difícilmente tienen fuera de la ficción: los relatos los dotan de corporeidad pero sobre todo de voz, con lo cual se consigue desdibujar otra frontera poética: la separación entre ficción y no ficción se difumina. En el corpus literario aquí estudiado, el tema de la frontera se coloca en el intersticio de la ficción y la no-ficción, entre el discurso testimonial, la memoria y la historia. Sus relatos no pueden comprenderse sin la idea de violencia, sin el conjunto de estadísticas que indica a penas la cantidad de indocumentados que no logran cruzar "al otro lado", o sin la fotografía de abusos que acepta el sujeto migrante cuando ha logrado su cometido: estar en territorio de otros vuelve ajeno todo; conduce no "a una suerte de", sino a una clara y tremenda despersonalización y anulación del sujeto. La meta es lo que importa, ya sea cruzar la frontera sur o la frontera norte.

Ante el proceso de desplazamiento forzado y el inminente enfrentamiento a los desafíos que implica cruzar la frontera, la narrativa centroamericana elabora y expresa un discurso testimonial en el que la voz está signada no sólo por la denuncia social o política, sino por una configuración de una identidad narrativa que se arropa por una retórica y una poética de la hibridación bien lograda, en tanto despliega, entre los bordes y pliegues de sus narraciones, la tradición en la que se inscribe. La literatura centroamericana posee una larga tradición que significa, desde una mirada artística, la fragmentación de su territorio y la separación entre sus individuos. Sin embargo, también es muestra notoria de la corrupción social y política que como nube negra cubre toda América Latina. 
Narraciones breves y largas, como las aquí comentadas, manifiestan, por un lado, las diferencias sociales internas entre habitantes de un mismo territorio (raciales, culturales, económicas, religiosas, etc.) y, por otro, estas mismas diferencias representadas a través de la literatura son las que aproximan y homogenizan la condición centroamericana y la vuelven una.

\section{Bibliografía}

Aguayo, Sergio, 1985, El éxodo centroamericano. Consecuencias de un conflicto, México, SEP.

Aguilera-Malta, Demetrio, 1977, Canal Zone, México, Joaquín Mortiz.

Arias, Arturo, 2000, "Bocado de viento", en Cuentos centroamericanos, Poli Délano (comp.), Barcelona, Editorial Andrés Bello, pp. 15-42.

Arroyo, Justo, 2010, "La pregunta", en El cuento hispanoamericano, Seymour Menton (ant.), México, FCE, pp. 731-735.

Bahr, Eduardo, 2000, "Los héroes de la fiebre", en Cuentos centroamericanos, Poli Délano (comp.), Barcelona, Editorial Andrés Bello, pp. 69-78.

Belausteguigoitia, Marisa, 2009, "Frontera”, en Mónica Szurmuk y Robert Mckee Irwin (coord.), Diccionario de estudios culturales latinoamericanos, México, Siglo XXI, pp. 106- 111

Castellanos Moya, Horacio, 2001, El arma en el hombre, México, Tusquets.

Castillo, Manuel Ángel, 1998, "La política de inmigración en México: Un breve recuento", en Manuel Ángel Castillo et al. (coord.), Migración y fronteras, México, El Colegio de la Frontera Norte/Colmex/Asociación Latinoamericana de Sociología, pp. 425-451. 
Chamorro Cardenal, Pedro Joaquín, 1957, Estirpe sangrienta: los Somoza, México, Patria y Libertad.

Chávez Alfaro, Lizandro, 2000, "El zoológico de papá”, en Cuentos centroamericanos, Poli Délano (comp.), Barcelona, Editorial Andrés Bello, pp. 143-148.

Cuevas Velasco, Norma Angélica y Raquel Velasco González (coord.), 2011, El norte y el sur de México en la diversidad de su literatura, México, Juan Pablos Editor.

Délano, Poli, 2000, Cuentos centroamericanos, Barcelona, Editorial Andrés Bello.

García Canclini, Néstor, 2001, Culturas hibridas. Estrategias para entrar y salir de la modernidad, México, Grijalbo.

García Canclini, Néstor, 2003, "Noticias recientes sobre hibridación", Transcultural Music Review, vol. 7. Disponible en: www. sibetrans.com/trans/trans7/canclini.htm (consultado: 26/ III/2017).

García de la Sienra, Rodrigo y Raquel Velasco (coord.), 2014, La migración y sus narraciones, Houston, Literal Publishing.

Gómez, Leila, 2009, “Hibridez”, en Mónica Szurmuk y Robert Mckee Irwin (coord.), Diccionario de estudios culturales latinoamericanos, México, Siglo XXI, pp. 134-139.

Jameson, Fredric, 2004, Una modernidad singular. Ensayo sobre la ontología del presente, Barcelona, Gedisa.

Lara Klahr, Marco, 2006, Hoy te toca la muerte. El imperio de las Maras visto desde dentro. México, Planeta,

Menton, Seymour, 2010, El cuento hispanoamericano, México, FCE.

Palacios, Oscar, 1993, La mitad del infierno, Chiapas, Gobierno del Estado de Chiapas/ Consejo Estatal de Fomento a la Investigación y Difusión de la Cultura/DIF-Chiapas/ Instituto Chiapaneco de la Cultura. 
Pantxika Cazaux, 1983, "Guatemala hoy”, en Casa del tiempo, vol. III, núms. 31 y 32, México, UAM, pp. 29-35.

Pimentel, Aurora, 1998, El relato en perspectiva. Estudio de teoría narrativa, México, Siglo XXI,

Rey Rosa, Rodrigo, 2001, Piedras encantadas. España, Seix Barral.

Santos-Febres, Mayra, 2006, Nuestra Señora de la noche, Madrid, Espasa-Calpe.

Simonovis, Leonora, 2010, "Isabel Luberza Oppenheimer: variaciones de una misma plena”. Disponible en: http://dialnet.unirioja.es/servlet/articulo?codigo=3304201 (consultado: 8/11/2011).

Szurmuk, Mónica y Robert Mckee Irwin (coord.), 2009, Diccionario de estudios culturales latinoamericanos, México, Siglo XXI.

Vadillo Buenfil, Carlos, 2004, Te están buscando, Málaga, Editorial Arguval. 